\title{
Influence of Changes in Body Composition and Adaptive Thermogenesis on the Difference between Measured and Predicted Weight Loss in Obese Women
}

\author{
Kristin Goele Anja Bosy-Westphal Birgit Rümcker Merit Lagerpusch Manfred J. Müller \\ Institute of Human Nutrition and Food Science, Christian-Albrechts-University Kiel, Germany
}

\section{Key Words}

Dietary treatment $\cdot$ Body composition .

Adaptive thermogenesis

\section{Summary}

Background: There is a difference between measured and predicted weight loss in obese patients. This might be explained by the composition of weight loss, adaptive thermogenesis, or poor compliance. Patients and Methods: 48 overweight and obese female patients $(31.5 \pm 6.1$ years; BMI $35.4 \pm 4.4 \mathrm{~kg} / \mathrm{m}^{2}$ ) were investigated before and $13.9 \pm 2.4$ weeks after dietary treatment $(1,000 \mathrm{kcal} /$ day $)$. Body composition was measured by air-displacement plethysmography and resting energy expenditure (REE) by indirect calorimetry. Physical activity was assessed using electronic pedometers in order to calculate total energy expenditure from REE and physical activity level (PAL). Fat mass (FM) and fat-free mass (FFM) were converted into caloric equivalents using $9.45 \mathrm{kcal} / \mathrm{g} \mathrm{FM}$ and $1.13 \mathrm{kcal} / \mathrm{g} \mathrm{FFM}$. Predicted weight loss was calculated by Wishnofsky's ' $7,700 \mathrm{kcal} / \mathrm{kg}$ rule'. Results: Weight $(-8.4 \pm$ $3.9 \mathrm{~kg} ; \mathrm{p}<0.001), \mathrm{FM}(-7.8 \pm 3.6 \mathrm{~kg} ; \mathrm{p}<0.001)$, and FFM $(-0.6 \pm 2.0 \mathrm{~kg} ; \mathrm{p}<0.05)$ decreased with caloric restriction. Measured weight loss was only $44 \%$ of the predicted value. Since FM contributed to $87 \%$ of weight loss, the energy deficit/kg weight loss was considerably higher $(9,098 \pm 2,349 \mathrm{kcal} / \mathrm{kg})$ than the assumed $7,700 \mathrm{kcal} / \mathrm{kg}$. Adaptive thermogenesis after weight loss was significant in 26 of 48 women $(-3.2 \pm 1.2 \mathrm{kcal}$ per kg FFM; $\mathrm{p}<0.001)$. Conclusion: $14 \%$ of the difference between measured and predicted weight loss was explained by the higher proportion of FM in weight loss and $38 \%$ by adaptive thermogenesis (in $54 \%$ of the women). Thus, poor compliance was responsible for about $50 \%$ of the difference between measured and predicted weight loss only.

\section{Introduction}

Low-calorie diets (LCD) are frequently used in the treatment of obesity. In order to predict weight loss at a given energy deficit or to calculate the required energy deficit for a certain aim of weight loss, the most pervasive rule of Wishnofsky from 1952 is used [1]. Wishnofsky's rule is based on the assumption of a cumulative energy deficit of 7,700 kcal (32.2 MJ) per kg body weight loss that requires a fixed composition of weight loss, i.e. $79 \%$ fat mass (FM) and $21 \%$ fat-free mass (FFM). However, in clinical practice, the actual composition of weight loss is highly variable and the proportion of \%FFM of weight loss may reach up to $53 \%$ [2]. The rate of weight loss and the effect of variations in protein intake on losses in FFM have been discussed [2, 3]. In a meta-analysis, Krieger et al. [3] had combined the results of 87 dietary intervention trials ( $\geq 4$ weeks, $\geq 1,000 \mathrm{kcal} / \mathrm{day}$ ) and observed that protein intake was a significant predictor of FFM retention.

Measured weight loss with LCD is often less than the predicted value [4-6]. This is most frequently explained by a poor compliance of the patients, particularly because of an increase in hunger and the desire to eat during energy restriction [4, 7-9]. In addition, adaptive thermogenesis defined as reduced resting energy expenditure (REE) per kg FFM may add to the low success of weight loss interventions $[5,10]$. Over the last 80 years, the presence of adaptive thermogenesis has been discussed controversially but did not attract interest in the clinical context [5]. Ravussin et al. [11] disproved the existence of adaptive thermogenesis associated with LCD, whereas other studies found an adaptive reduction in REE in response to caloric restriction in obese subjects $[5,12,13]$. However, the exact contributions of the variance in body composition, specific energy expenditure, and non-compliance to diet-induced weight loss have not been calculated.

\section{KARGER}

Fax +497614520714

Information@Karger.de

www.karger.com (c) 2009 S. Karger GmbH, Freiburg

Accessible online at:

www.karger.com/ofa
Prof. Dr. med. Manfred J. Mülle

Institut für Humanernährung und Lebensmittelkund

Christian-Albrechts-Universität zu Kiel

Düsternbrooker Weg 17-19, 24105 Kiel, Germany

Tel. +49 431 88056-70, Fax -79

mmueller@nutrfoodsc.uni-kiel.de 
The aim of this study was to examine the contribution of i) the composition of weight loss and ii) adaptive thermogenesis to the difference between measured and predicted weight loss. In addition, we analyzed the effect of the rate of weight loss and protein content of the diet on the composition of weight loss.

\section{Patients and Methods}

\section{Study Design and Population}

A group of 59 healthy overweight and obese women (age $32.0 \pm 6.2$ years; BMI $35.1 \pm 4.2 \mathrm{~kg} / \mathrm{m}^{2}$ ) was recruited by notice board posting and advertisement in the local newspaper for a diet-induced weight loss program. Exclusion criteria were smoking, pregnancy or breastfeeding, cardiovascular diseases, diabetes mellitus, or regularly used medications with influence on body composition or REE. Seven women (12\%) dropped out because of personal reasons ( 3 cases) and unsuccessful weight loss $(<2$ $\mathrm{kg}$ in 6 weeks; 4 cases). Data from 4 women were excluded because the achieved weight loss was $<4 \mathrm{~kg}$. The remaining 48 women (22-41 years; BMI $28.6-46.5 \mathrm{~kg} / \mathrm{m}^{2}$ ) were included in this study. The study protocol was approved by the local ethical committee of the Christian-Albrechts-University Kiel. Each participant provided written informed consent before participation.

During the $13.9 \pm 2.4$ weeks of weight loss intervention, the women consumed a low-calorie, nutritionally balanced diet $(1,000 \mathrm{kcal} / \mathrm{day}) \mathrm{con}-$ sisting of two meals of a formula diet $\left(\mathrm{BCM}^{\circledR}\right.$-Diät, PreCon, Darmstadt, Germany) and a low-fat meal per day. One meal of the formula diet contained $205 \mathrm{kcal}$, including $18.7 \mathrm{~g}$ protein, $17.4 \mathrm{~g}$ carbohydrates, and $6.7 \mathrm{~g}$ fat. The low-fat meal contained a maximum of $450 \mathrm{kcal}$ and consisted mainly of vegetables and a portion size of either $100 \mathrm{~g}$ meat or $150 \mathrm{~g}$ fish. In addition, 7 'bonus' portions of $100 \mathrm{kcal} /$ day each were allowed during the week. All women obtained individual counselling in the principles of the hypocaloric diet by a registered dietitian. They were also instructed to keep a daily food record to monitor the dietary composition of the low-fat meal.

\section{Anthropometric Measurements and Body Composition Analysis}

Body height was measured to the nearest $1.0 \mathrm{~cm}$ with a stadiometer (Seca, Vogel and Halke GmbH and Co, Hamburg, Germany). Body weight was assessed to the nearest gram by an electronic scale coupled to the BOD $\mathrm{POD}^{\circledR}$ system (Body Composition System; Life Measurement Instruments, Concord, CA, USA). Body composition (FM and FFM) was assessed by air displacement plethysmography $\left(\mathrm{BOD}^{\mathrm{POD}}{ }^{\circledR}\right)$ as described elsewhere [14]

\section{Calculation of the Energy Deficit of Weight Loss}

In order to calculate the energy deficit of weight loss, losses in FM and FFM were converted into kilocalories using the caloric equivalents: $1 \mathrm{~g}$ $\mathrm{FM}=9.45 \mathrm{kcal}$ and $1 \mathrm{~g} \mathrm{FFM}=1.13 \mathrm{kcal}$, with an assumed protein content of $20 \%$ in FFM $[1,15]$.

\section{Assessment of Resting and Total Energy Expenditure}

Indirect calorimetry was performed using a ventilated hood system (Vmax Spectra 29n; SensorMedics; Viasys Healthcare, Bilthoven, The Netherlands; software Vmax, version 12-1A) which was described elsewhere [16]. REE was adjusted for FFM (REE adjFFM ) according to Ravussin and Bogardus [17]. Physical activity was measured using electronic pedometers (Walking Style pro; OMRON Healthcare, Mannheim, Germany) for 25-50 days to reach a reliable estimate of daily step counts. For each woman, a physical activity level (PAL) was calculated from the mean step counts per day. Less than 5,000 steps/day were attributed to a PAL of 1.2 (sedentary activity), 5,000-7,499 steps/day to 1.5 (low activity), and $7,500-9,999$ steps/day to 1.6 (slightly active) [18]. As the step counts of 10 women were missing, a PAL of 1.5 was assumed for these participants. Total energy expenditure (TEE) was calculated as the product of PAL and REE. Energy deficit was calculated from the difference between TEE and energy intake (1,000 kcal/day).

\section{Statistical Analysis}

Graphical and statistical analyses were performed using Microsoft Excel 2003 (Redmond, WA, USA) and SPSS 13.0 (Chicago, IL, USA) for Windows. All data are given as means \pm standard deviation (SD). Differences were tested by paired samples t-test. Pearson's correlation was used to demonstrate the relationship between two variables. To explain the variance in losses of FFM, multiple step-wise regression analysis was performed with the following independent variables: rate of weight loss, initial body weight, and protein intake/day. $\mathrm{p}<0.05$ (two-sided) was considered as statistically significant.

\section{Results}

\section{Characterization of the Study Population}

Weight $(-8.4 \pm 3.6 \%)$, BMI $(-8.5 \pm 3.5 \%)$, FM $(-4.4 \pm 2.8 \%)$, and FFM $(-0.9 \pm 3.7 \%)$ significantly decreased after $13.9 \pm 2.4$ weeks of weight loss (table 1). Decreases in weight loss and BMI ranged from -4.0 to $-16.0 \mathrm{~kg}$ and from -1.5 to $-6.1 \mathrm{~kg} / \mathrm{m}^{2}$, respectively. FM and FFM were reduced by -1.3 to $-17.6 \mathrm{~kg}$ and -4.0 to $2.8 \mathrm{~kg}$, respectively.

\section{Changes in Body Composition and Difference between Measured and Predicted Weight Loss}

A comparison between measured weight loss and weight loss predicted by the '7,700 $\mathrm{kcal} / \mathrm{kg}$ rule' [1] showed that weight loss was overestimated by the prediction (fig. 1). Measured weight loss was only $44 \%$ of the predicted value (table 2 ). The composition of weight loss differed from estimated values. Weight loss of $1 \mathrm{~kg}$ consisted of 87\% FM (51-98\%) and 13\% FFM (2-49\%) instead of estimated 79\% FM and 21\% FFM. The decrease in FFM correlated with the rate of weight loss $(0.43 ; \mathrm{p}<0.01)$ and initial body weight $(0.31 ; \mathrm{p}<0.05)$ and was inversely associated with protein intake $/ \mathrm{kg}$ body weight $(-0.30 ; \mathrm{p}<0.05)$. There were no associations between the decrease in FFM, initial FM at baseline, and duration of weight loss. In a multiple step-wise regression analysis, $18 \%$ of the variance in loss of FFM was explained by the rate of weight loss, whereas initial body weight and protein intake/day did

Table 1. Age and nutritional status of the study population before (T0) and after $13.9 \pm 2.4$ weeks of weight loss $(\mathrm{T} 1)(\mathrm{n}=48)$

\begin{tabular}{lcll}
\hline & T0 & T1 & $\Delta \mathrm{T} 1-\mathrm{T} 0$ \\
\hline Age, years & $31.5 \pm 6.1$ & - & - \\
Height, cm & $168.7 \pm 8.0$ & - & - \\
Weight, kg & $100.6 \pm 17.6$ & $92.2 \pm 16.9$ & $-8.4 \pm 3.9^{* * *}$ \\
BMI, kg/m & $35.4 \pm 4.4$ & $32.2 \pm 4.2$ & $-3.0 \pm 1.3^{* * * *}$ \\
FM, kg & $47.6 \pm 12.6$ & $39.8 \pm 15.5$ & $-7.8 \pm 3.6^{* * *}$ \\
FFM, kg & $52.9 \pm 7.1$ & $52.3 \pm 6.5$ & $-0.6 \pm 2.0^{*}$ \\
\hline
\end{tabular}

$* * * \mathrm{p}<0.001 ; * \mathrm{p}<0.05$ (paired t-test). 
Table 2. Daily energy deficit during weight loss as well as the comparison between predicted weight loss according to ' $7,700 \mathrm{kcal} / \mathrm{kg}$ rule' and measured weight loss $(\mathrm{n}=48)$

\begin{tabular}{|c|c|c|c|c|}
\hline & $\begin{array}{l}\text { Daily energy } \\
{\text { deficit, } \mathrm{kcal}^{\mathrm{a}}}^{\text {a }}\end{array}$ & $\begin{array}{l}\text { Predicted } \\
\text { weight loss, } \mathrm{kg}^{\mathrm{b}}\end{array}$ & $\begin{array}{l}\text { Measured } \\
\text { weight loss, } \mathrm{kg}\end{array}$ & $\begin{array}{l}\Delta \text { predicted to measured } \\
\text { weight loss, } \mathrm{kg}\end{array}$ \\
\hline Mean \pm SD & $1,536 \pm 399$ & $19.27 \pm 5.14$ & $8.44 \pm 3.94$ & $10.83 \pm 6.00^{* * *}$ \\
\hline Range & $700-2,550$ & $7.69-29.83$ & $1.56-19.34$ & $-0.62-27.43$ \\
\hline
\end{tabular}

${ }^{a}$ Energy deficit was calculated as the difference between total energy expenditure and daily energy intake $(1,000 \mathrm{kcal})$.

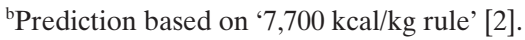

$* * * \mathrm{p}<0.001$ (paired t-test).
Table 3. Comparison between weight loss according to measured energy deficit and energy deficit estimated by ' $7,700 \mathrm{kcal} / \mathrm{kg}$ rule' $(\mathrm{n}=48)$

\begin{tabular}{lllll}
\hline & $\begin{array}{l}\text { Measured energy } \\
\text { deficit, kcal/kg }\end{array}$ & \multicolumn{2}{c}{ Predicted weight loss according to, kg } & \multirow{2}{*}{$\Delta$ weight loss $^{\mathrm{b}}, \mathrm{kg}$} \\
\cline { 3 - 4 } & & measured energy deficit & estimated energy deficit ${ }^{\mathrm{a}}$ & \\
\hline Mean \pm SD & $9,098 \pm 2,349$ & $18.3 \pm 8.8$ & $19.8 \pm 6.4$ & $-1.5 \pm 6.5^{*}$ \\
Range & $3,097-16,401$ & $7.2-30.1$ & $7.7-29.8$ & -10.4 to 32.3 \\
\hline
\end{tabular}

${ }^{a}$ Based on the assumption that the caloric equivalent of $1 \mathrm{~g} \mathrm{FM}$ is $9.45 \mathrm{kcal}$ and $1 \mathrm{~g} \mathrm{FFM} \mathrm{is} 1.13 \mathrm{kcal}$.

${ }^{\mathrm{b}}$ Measured energy deficit minus estimated energy deficit.

*p $<0.05$ (paired t-test). not significantly contribute to the model. Measured energy deficit/kg weight loss calculated from the composition of lost weight (87\% FM / 13\% FFM) as well as a comparison between weight loss according to measured energy deficit and energy deficit estimated by the $7,700 \mathrm{kcal} / \mathrm{kg}$ rule are shown in table 3. Measured energy deficit/kg weight loss $(9,098 \pm 2,349$ $\mathrm{kcal} / \mathrm{kg}$ ) was considerably higher than the estimated value of $7,700 \mathrm{kcal} / \mathrm{kg}$. The deviation between measured and estimated energy deficit explained $14 \%(1.5 \pm 6.5 \mathrm{~kg})$ of the difference between measured and predicted weight loss.

\section{Adaptive Thermogenesis and Difference between Measured and Predicted Weight Loss}

After weight loss, REE and REE adjFFM $_{\text {decreased by } 5.6 \% \text { and }}$ TEE decreased by $5.7 \%$ (table 4 ). Mean step count was 6,520 $\pm 2,084(2,250-10,600)$ steps per day corresponding to a low activity level $(\mathrm{PAL}=1.5)$. After caloric restriction, a decrease in REE per $\mathrm{kg}$ FFM (less than $-1.5 \mathrm{kcal} / \mathrm{kg}$ ) was observed in 26 women $(-3.2 \pm 1.2 \mathrm{kcal} / \mathrm{kg}$ FFM; $\mathrm{p}<0.001)$ (fig. 2). By contrast, REE per kg FFM did not change with weight loss in the other 22 women $(-0.6 \pm 1.4 \mathrm{kcal} / \mathrm{kg} ; \mathrm{p}=0.074)$. Rate and composition of weight loss in the 26 women who showed an adaptive thermogenesis did not differ from those without adaptive thermogenesis (weight loss $-0.60 \pm 0.27$ vs. $-0.62 \pm$ $0.38 \mathrm{~kg} /$ week; FM $-7.0 \pm 3.5 \mathrm{~kg}$ vs. $-8.5 \pm 3.5 \mathrm{~kg}$; FFM $-1.1 \pm$ $1.8 \mathrm{~kg}$ vs. $-0.2 \pm 2.1 \mathrm{~kg}$ FFM). Adjusting the weight loss prediction according to Wishnofsky [1] for adaptive thermogenesis in 26 women, a significant difference between predicted and measured weight loss remained $(6.4 \pm 6.0 \mathrm{~kg} ; \mathrm{p}<0.001)$. Thus, adaptive thermogenesis explained $38 \%(-4.3 \pm 2.9 \mathrm{~kg})$ of the difference between measured and predicted weight loss in this group of women.
Fig. 1. Comparison between measured weight loss and weight loss predicted by the ' $7,700 \mathrm{kcal} / \mathrm{kg}$ rule' [2] after $13.9 \pm$ 2.4 weeks of caloric restriction $(n=48)$.

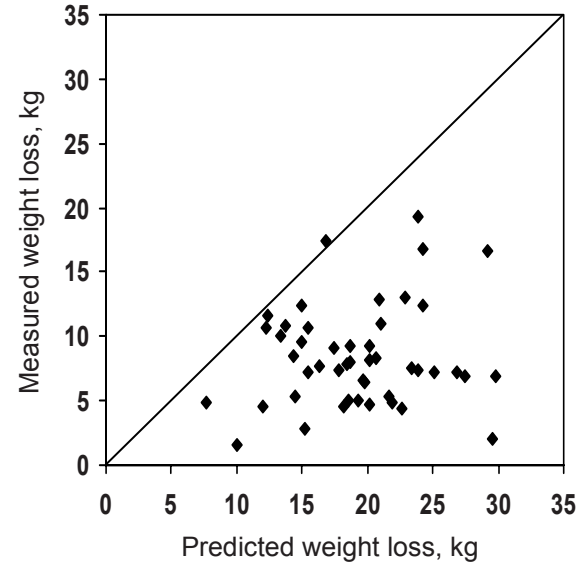

\section{Discussion}

The results show that body composition changes add to weight loss in response to dieting. FM was lost at a higher proportion of weight than was hypothesized in Wishnofsky's '7,700 kcal/ kg rule' [1]. In the whole study population, body composition explained $14 \%$ of the difference between measured and predicted weight loss, and in $54 \%$ of the subjects adaptive thermogenesis further explained $38 \%$ of this difference. Thus, in these women, poor compliance explained $50 \%$ of the discrepancy between measured and predicted weight loss only.

\section{Changes in Body Composition and Difference between Measured and Predicted Weight Loss}

LCD are a cornerstone in the treatment of obese persons but the low efficacy of LCD limits its acceptance $[1,4]$. In the present study, the composition of lost weight and adaptive 
Table 4. REE, TEE, and physical activity before (T0) and after weight loss (T1) (n=48)

\begin{tabular}{llll}
\hline & $\mathrm{T} 0$ & $\mathrm{~T} 1$ & $\Delta \mathrm{T} 1-\mathrm{T} 0$ \\
\hline REE, kcal/day & $1,726 \pm 220$ & $1,635 \pm 218$ & $-92 \pm 134 * * *$ \\
$\mathrm{REE}_{\text {adjFm }}, \mathrm{kcal} / \mathrm{day}$ & $1,702 \pm 198$ & $1,623 \pm 152$ & $-79 \pm 135^{* * * *}$ \\
Step counts, steps/day & $6,520 \pm 2,084$ & - & - \\
PAL & $1.5 \pm 0.2$ & - & - \\
TEE, kcal/day & $2,537 \pm 399$ & $2,400 \pm 372$ & $-137 \pm 204 * * *$ \\
\hline
\end{tabular}

*** $\mathrm{p}<0.001$ (paired t-test).

thermogenesis were analyzed since they might relate to poor success during LCD treatments. Our obese patients reached only $44 \%$ of their predicted weight loss (table 2 ). Similar results were reported in the review published by Heymsfield et al. [4]. These authors systematically reviewed LCD studies of non-diabetic overweight and obese subjects published in the New England Journal of Medicine and JAMA over the past 5 years. In 16 intervention studies with a duration $\geq 26$ weeks, the average weight loss ranged from 1.7 to $8.1 \mathrm{~kg}$, representing $11-45 \%$ of the predicted value. Interindividual variability in weight loss was high and ranged from 7.1 to $103.5 \%$ of the predicted value.

The weight loss rule by Wishnofsky was based on a fixed composition of weight loss (79\% FM / 21\% FFM) [1]. In our study, the average proportion of FM in weight loss $(87 \%)$ was considerably higher than the estimated value of $79 \%$, but the interindividual variability of the composition of weight loss was high (FM 51-98\%; FFM 2-49\%). The loss in FFM increased with higher initial body weight and rate of weight loss. Since a higher initial body weight reflects a higher energy requirement and thus a higher energy deficit during LCD, it was associated with the rate of weight loss as well as the loss in FFM. In agreement with these findings, Chaston et al. [2] demonstrated that dietary-induced losses in FFM increased with energy deficit and thus with the rate of weight loss. In addition, losses in FFM decreased with a higher protein intake/day (see results) because protein has been shown to be a significant predictor of FFM retention [3]. Krieger et al. [3] determined that a high protein intake of $>1.05 \mathrm{~g} / \mathrm{kg}$ body mass during energy restriction was associated with a greater FFM retention when compared with protein intake closer to the Recommended Dietary Allowance (RDA) $(0.8 \mathrm{~g} / \mathrm{kg}$ body mass). As the RDA for protein has been calculated for weight-stable conditions and isocaloric nutrition, this value is not sufficient for FFM retention during energy restriction. However, during a prolonged period of dieting, energy restriction could decrease the nitrogen balance and therefore the amount of protein and FFM retained by the body. In the present study, daily protein intake was calculated from daily food records and varied from $0.5-0.9 \mathrm{~g}$ protein $/ \mathrm{kg}$ body mass which was i) below or close to the RDA for protein as well as

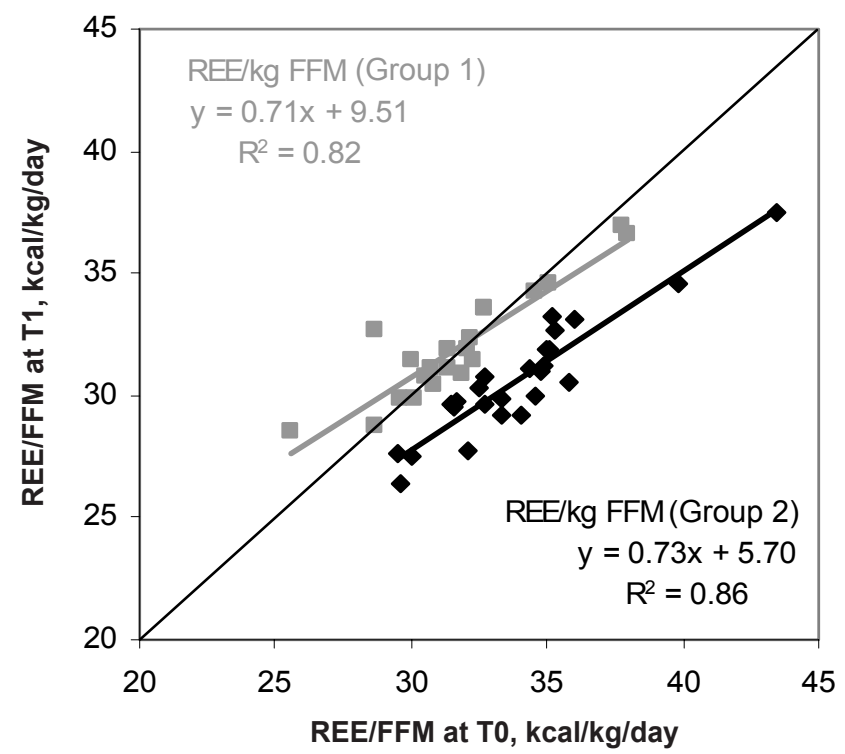

Fig. 2. Relationship between REE per kg FFM at baseline (T0) and during follow-up (T1); Group 1: subjects who did not show an adaptive thermogenesis $(\mathrm{n}=22)$; Group 2: subjects who showed an adaptive thermogenesis $(n=26)$.

ii) in the range of the recommendation that was determined for FFM retention during energy restriction ( $>1.05 \mathrm{~g}$ protein/ $\mathrm{kg}$ ) [3]. Thus, during energy restriction, daily protein intake should be adjusted to achieve a high FFM retention.

Energy deficits of lost weight were significantly higher than the hypothesized 7,700 kcal due to a higher proportion of FM in weight loss $(87 \%)$ (table 3). Several studies have already attempted to validate the energy content of the weight change 'constant' in different dietary interventions. Pietrobelli et al. [19] showed that estimated energy contents of weight change in women $(7,188-7,700 \mathrm{kcal} / \mathrm{kg})$ were close to the estimated value of $7,700 \mathrm{kcal} / \mathrm{kg}$. By contrast, Dole et al. [25] observed a low value for the energy content of weight change $(2,627$ $\mathrm{kcal}$ ) in women during 4-day over- and underfeeding. We may deduce from these results and our own data that Wishnofsky's rule [1] is not universally applicable and should be considered cautiously. It is likely that other factors play a role in the composition of weight loss, e.g. exercise or sustained energy restriction may modify the composition of lost weight [20]. However, the difference between measured and assumed composition of weight loss explained $14 \%$ of the difference between measured and predicted weight loss only.

\section{Adaptive Thermogenesis and Difference between Measured and Predicted Weight Loss}

The significant reduction in $\mathrm{REE}_{\mathrm{adjFF}}$ after caloric restriction (table 4) supports an adaptive thermogenesis in response to decreased energy intake which has been discussed controversially in the literature for many years [5]. Astrup et al. [21] conducted a meta-analysis based on 17 studies comparing $\mathrm{REE}$ in formerly obese subjects and matched control persons 
who had never been obese. In 13 studies, there were no significant differences between REE in formerly obese and control subjects. Only 4 studies reported a significant reduction in REE in formerly obese subjects. In another review, Major et al. [5] confirmed the existence of an adaptive thermogenesis in response to caloric restriction in obese patients. These authors also concluded that metabolic adaptations varied substantially among individuals. Individual differences in metabolic responses to weight change were also reported by Weyer et al. [12] and were in agreement with the results from the present study. Adaptive thermogenesis was found in 26 of 48 women (54\%) only ( $-3.2 \pm 1.2 \mathrm{kcal} / \mathrm{kg}$ FFM) (fig. 2). Adaptive thermogenesis is explained by neuroendocrine adaptation to caloric restriction [5], including a reduced activity of the sympathetic nervous system as well as decreased plasma concentrations of leptin and thyroid hormones [22].

\section{Study Limitations}

Body composition (FM/FFM) was measured by air-displacement plethysmography that has been shown to be a reliable technique providing precise measurements of changes in body composition in obese subjects [23]. However, increased hydration of FFM in obesity might lead to an overestimation of FM. If hydration of FFM decreases with weight loss, this would lead to an overestimation of losses in FM [24]. A second limitation of the study was the assumption of a low activity level (PAL 1.5) for 10 patients with missing step count data. As the mean activity level of our study population was generally low (table 4), we assumed the same low PAL for the missing data.

\section{Conclusion}

In obese patients, changes in body composition and adaptive thermogenesis significantly add to the outcome of diet-induced weight loss. Since $50 \%$ of the difference between measured and predicted weight loss was not explained by the composition of weight loss or adaptive thermogenesis, poor compliance significantly contributes to the variance in weight loss.

\section{Acknowledgement}

The study was supported by a grant of the Deutsche Forschungsgemeinschaft (DFG Mü 714/8-3).

\section{Disclosure}

The authors declared no conflict of interest.

\section{References}

1 Wishnofsky M: Caloric equivalents of gained or lost weight. Am J Clin Nutr 1958;6:542-546.

2 Chaston TB, Dixon JB, O'Brien PE: Changes in fat-free mass during significant weight loss: a systematic review. Int J Obes (Lond) 2007;31:743-750.

-3 Krieger JW, Sitren HS, Daniels MJ, LangkampHenken B: Effects of variation in protein and carbohydrate intake on body mass and composition during energy restriction: a meta-regression 1 . Am J Clin Nutr 2006;83:260-274.

4 Heymsfield SB, Harp JB, Reitman ML, Beetsch JW, Schoeller DA, Erondu N, Pietrobelli A: Why do obese patients not lose more weight when treated with low-calorie diets? A mechanistic perspective. Am J Clin Nutr 2007;85:346-354.

$\checkmark 5$ Major GC, Doucet E, Trayhurn P, Astrup A, Tremblay A: Clinical significance of adaptive thermogenesis. Int J Obes (Lond) 2007;31:204-212.

6 Wamsteker EW, Geenen R, Iestra J, Larsen JK, Zelissen PM, van Staveren WA: Obesity-related beliefs predict weight loss after an 8-week lowcalorie diet. J Am Diet Assoc 2005;105:441-444.

7 Pudel V, Westenhöfer J: Ernährungspsychologie. Eine Einführung, ed 3. Göttingen, Hogrefe, 2003.

$\checkmark 8$ Chaput JP, Drapeau V, Hetherington M, Lemieux S, Provencher V, Tremblay A: Psychobiological effects observed in obese men experiencing body weight loss plateau. Depress Anxiety 2007;24:518-521.

$\checkmark 9$ Dulloo AG: Suppressed thermogenesis as a cause for resistance to slimming and obesity rebound: adaptation or illusion? Int J Obes (Lond) 2007;31:201-203.
10 Doucet E, St-Pierre S, Almeras N, Despres JP, Bouchard C, Tremblay A: Evidence for the existence of adaptive thermogenesis during weight loss. Br J Nutr 2001;85:715-723.

11 Ravussin E, Burnand B, Schutz Y, Jequier E: Energy expenditure before and during energy restriction in obese patients. Am J Clin Nutr 1985;41:753-759.

12 Weyer C, Pratley RE, Salbe AD, Bogardus C, Ravussin E, Tataranni PA: Energy expenditure, fat oxidation, and body weight regulation: a study of metabolic adaptation to long-term weight change. $\mathrm{J}$ Clin Endocrinol Metab 2000;85:1087-1094.

13 Rosenbaum M, Hirsch J, Gallagher DA, Leibel RL: Long-term persistence of adaptive thermogenesis in subjects who have maintained a reduced body weight. Am J Clin Nutr 2008;88:906-912.

14 Bosy-Westphal A, Danielzik S, Becker C, Geisler C, Onur S, Korth O, Bührens F, Müller MJ: Need for optimal body composition data analysis using air-displacement plethysmography in children and adolescents. J Nutr 2005;135:2257-2262.

15 Diaz EO, Prentice AM, Goldberg GR, Murgatroyd PR, Coward WA: Metabolic response to experimental overfeeding in lean and overweight healthy volunteers. Am J Clin Nutr 1992;56:641-655.

16 Bader N, Bosy-Westphal A, Dilba B, Müller MJ: Intra- and interindividual variability of resting energy expenditure in healthy male subjects - biological and methodological variability of resting energy expenditure. Br J Nutr 2005;94:843-849.

17 Ravussin E, Bogardus C: Relationship of genetics, age, and physical fitness to daily energy expenditure and fuel utilization. Am J Clin Nutr 1989;49:968-975.
18 Müller MJ, Boeing H, Bosy-Westphal A, Löser C, Przyrembel H, Selberg O, Weimann A, Westenhöfer J: Ernährungsmedizinsche Praxis, ed 2. Heidelberg, Springer, 2007.

19 Pietrobelli A, Allison DB, Heshka S, Heo M, Wang ZM, Bertkau A, Laferrere B, Rosenbaum M, Aloia JF, Pi-Sunyer FX, Heymsfield SB: Sexual dimorphism in the energy content of weight change. Int J Obes Relat Metab Disord 2002;26:1339-1348.

20 Hall KD: What is the required energy deficit per unit weight loss? Int J Obes (Lond) 2008;32:573-576.

21 Astrup A, Gøtzsche PC, van de Werken K, Ranneries C, Toubro S, Raben A, Buemann B: Metaanalysis of resting metabolic rate in formerly obese subjects. Am J Clin Nutr 1999;69:1117-1122.

-22 Rosenbaum M, Murphy EM, Heymsfield SB, Matthews DE, Leibel RL: Low dose leptin administration reverses effects of sustained weight-reduction on energy expenditure and circulating concentrations of thyroid hormones. J Clin Endocrinol Metab 2002;87:2391-2394.

23 Fields DA, Higgins PB, Radley D: Air-displacement plethysmography: here to stay. Curr Opin Clin Nutr Metab Care 2005;8:624-629.

24 Le Carvennec M, Fagour C, Adenis-Lamarre E, Perlemoine C, Gin H, Rigalleau V: Body composition of obese subjects by air displacement plethysmography: the influence of hydration. Obesity (Silver Spring) 2007;15:78-84.

25 Dole VP, Schwartz IL, Thorn NA, Silver L: The caloric value of labile body tissue in obese subjects. J Clin Invest 1955;34:590-594. 